\title{
Moderating effect of organizational culture on the implementation of turnaround strategy
}

\author{
${ }^{1}$ Francis O. O. Ayiecha, ${ }^{2}$ Dr. Thomas A. Senaji \\ Jomo Kenyatta University of Agriculture and Technology (Kenya) \\ Kenya Methodist University (Kenya)
}

\begin{abstract}
Organizational culture cuts across most independent variables causing all manner of reactions on specific dependent variables especially where human resource behavioral aspect is at play in an organizational setup. This paper investigates the moderating effect of organizational culture on the implementation of turnaround strategy through a desktop research. Specifically, literature on turnaround strategy, its implementation, the factors at play during implementation with reference to business process reengineering as an independent variable and organizational culture's moderating effect on turnaround implementation strategy.
\end{abstract}

Key words: Organizational culture, Strategy implementation, Turnaround strategy

\section{Introduction}

There are a number of factors which influence the outcome of any implementation of turnaround strategy based on the independent variable under review. The independent variable in this study looks at business process reengineering (BPR) as a tool that most managers would opt to use in order to achieve competitive advantage. This is an ideal tool also for organizations which happen to be experiencing decline and hope to reverse the downward trend by cutting costs as well as reducing operations cycle time. A possible starting point foridentifyingthose factors or components of business process reengineering in research would be by looking at the already known critical success factors (CSFs) of BPR. According to Al-Mashari and Zairi (1999), there are five known business process reengineeing CSFs through reasearch namely change managemet, management competence, organizational structure, project management, and Information Technology (IT) infrastructurewhich form part of the factors under review.

However, looking at the way the BPR factors would influence the implementation of organizational turnaround strategy implementation, brings to the fore the fact that, organizational culture cuts across all of them since it involves human behavior which therefore implies that it would have a moderating effect between them. Desson and Clouthier (2010) attributed some of the reasons why culture was important in an organization to its ability to shape organization's capacity for and receptiveness to change, its ability to shape the speed and efficiency with which things are done among other reasons. This study will try to find out if organizational culture would have a moderating effect between the BPR components and that of turnaround strategy implementation. In the business world, organizations continue declining unabated while others go under liquidation eventually being declared insolvent. The ultimate aim of this paper is to give a clue and possible exposure on how the factors at play may be of benefit or used to reverse the trend of business declines and increase turnaround success rates.

\section{Literature Review}

The Stage theory of successful turnaround by Manimala (1991) identified four important stages in any successful turnarounds namely arresting sickness, focusing on core business, expansion and growth, and institutionalization through culture building. It lays emphasis on turnaround managers to adopt a stage wise procedure when implementing their strategies. The Causal Model of Organizational Performance and Change byBurke and Litwin (1992), may be used to, analyse, understand, and predict organizational change to provide some guidance when trying to understand how organizations work within situations of chaos. Organization that are in Turnaround situations would perfectly be considered to be in chaotic situations thereby requiring, either guidance in identification or the implication of the relationship between the factors and turnaround implementation strategy.

\section{Turnaround strategy and its implementation}

Wheelen and Hunger (2001) described Business Turnaround strategies as a form of retrenchment that emphasizes the improvement of operational efficiency. Turnaroundstrategy.net (2013) described a turnaround strategy as "an action plan that can give struggling business owners the guidance and direction they need to revitalize their company". Pandit (2000) suggested that any definition of turnaround should address the definition and measurement of performance; and the definition of turnaround cylce - that is a period of poor 
performance (decline phase) followed by a recovery in the performance (the recovery phase) and further emphasized that turnaround candidates are firms who's very existence is threatened unless radical action is taken and successful recovery cases demonistrate improved and sustainable environmental adaptation.Pretorius (2009) summarised and proposed a definition of turnaround using the following words, "a venture has been turned around when it has recovered from a decline that threatened its existence to resume normal operations and achieve performance acceptable to its stakeholders (constituents) through reorientation of positioning, strategy, structure, control systems and power distribution".

According to Burbank (2005) a five step turnaround process accepted and supported by the Global Association of Turnaround Professionals is composed of: stuation analysis, changing the management, emergency actions, and returning to normalcy (profiability).The purpose of turnaround strategy implementations in any company therefore, is to return the company back to a profitable and reducing debt situation and they are deemed to take a period of between five months even up to three years to complete, so that, if they were to be considered a success, then the company has to be financially strong and on its own for at least two years the turnaround plan is completed (Turnaroundstrategy.net, 2013).

John and Richard (1987) observed that business Turnaround strategy implementation, involved the reallocation of resources, in which management was, singled out as the most commonly reallocated resource. Lohrke, Bedeian and Palmer (2004) confirmed that, it was the top executives who's responsibility was, to formulating and implementing effective business turnaround strategies needed to reverse declining organizational performance.

Francis and Desai (2005) explored the ability of suituational variables, manageable pre-decline resources and specific responses to decline in order to classify performance outcomes in declining firms and found that contextual factors such as urgency, and severity of decline, firm productivity and the availability of slack resources and firm retrenchment would determine the ability of firms to turnaround. They concluded that "overall, factors under control of managers contributed more to successful turnarounds than situational characteristics".

Maheshwari (2000) suggested that choices available for turnaround, which would ensure improved performance, were leadership change, domain change, retrenchment of both assets and people, technology up gradation, cost reduction and HR interventions. Bruton, Ahlstrom and Wan (2001) found that in the west, a firm in decline had to retrench or reduce its expenses before it would begin the turnaround process, which was the same for East Asian firms. They further found that in the west a greater success occurred when the firm's turnaround efforts focused on the single most important cause of the firm's decline (operating or strategic problems), while in East Asia it was, reported that problems facing most firms had little to do with operating problems related to cost in the firm's core business. Further, in the west there was an assumption that the CEO of a firm had to be, replaced in a turnaround effort while in East Asia due to high levels of stock ownership by owner/manager in most cases at over 50\% CEO replacement in turnaround would not be mandatory. It was also, generally believed in both the west and East Asia that the faster the turnaround efforts began the more likely it would be successful.

Slatter, Lovett, and Barlow (2006) developed an approach for achieving a successful business turnaround or recovery plan whose seven essential ingredients were: crisis stabilisation; new leadership; stakeholder management; strategic focus; critical process improvements; organisational change; financial restructuring. They suggested that to succeed in realising critical process improvements during business turnaround of a company requires focus on cost, quality and time and that the generic business turnaround strategies to address the three focus areas were: improved sales and marketing; cost reduction; quality improvements; improved responsiveness and improved information and control systems.

They further emphasized that when considering production or operating strategies necessary for the effectiveness of business turnaround, some of the measures include raw material costs reduction, investment in R\&D and innovative technologies so as, to achieve competitive advantage. Hofer (1980) suggested that market penetration and niche positioning were, identified as valuable strategies for the successful corporate business turnarounds while according to Rosario, Kawamura and Peiris (2004) maintained that successful businesses competed on quality rather than on costs, with a view to developing competitive advantage. The measures for marketing strategies necessary to promote successful business turnaround include: promotional activities, aggressive pricing, entering newer markets and focusing on core business (Rosario, Kawamura, \& Peiris, 2004).Scherrer (2003) emphasized the need for a management turnaround to begin with the identification of a state of decline to be followed by an immediate turnaround although he attributed a successful turnaround to the presence of a strong management team and sound business core. He further clarifies that the key elements to any successful business turnaround were from the highest priority starting with: sound core business (that has salable product or service, proven market, operating assets and staff of capable perssonel); followed by leadership of competent management; then followed by capital for use throghout the process; and finally by the trust and 
support of the company's stakeholders. He however concludes that the frame of the turnaround will vary depending on the above elements and on the severity of the decline.

Panicker and Manimala (2011) suggested that bringing organizations back to health required entrepreneurial strategies at two levels namely from the negative to breakeven and from breakeven to the positive terming it "a doubly entrepreneurial act". Their study confirmed that "successful turnarounds were accomplished through progressive building up of organizational competencies in line with the stage theory(through strategies such as employee engagement, cost rationalization, lean management, image building, and focusing on core business) before taking up aggressive growth and expansion strategies". Maheshwari and Ahlstrom, Turning around a state owned enterprise: The case of scooters in India Limited (2003) found that: "the business environment; the firm's decision making process; its leadership characteristics; and the stakeholders' responses all influenced the firm's action choices and turnaround process". Haron, Rahman and Smith (2013) found that success of corporate turnaround was as a result of an effective leadership style capable of motivating and supporting the employees while making strategic changes on capital, financial well-being and operations of the organization.

\section{Turnaround strategy implementation factors}

Although there would be as many factors that influence turnaround strategy implementation as there are independent variables, it is quite in order to make an assumption that all the five components of business process reengineering critical success factors (CSFs) fall into the same category. Considering therefore, that the factors under review here then are organizational change, management competence, organizational structure, project management, and IT infrastructure they would be independently examined on how they interact with organizational culture in order to interpret the outcome on turnaround implementation.

\section{Organizational culture's moderating effect on turnaround strategy}

Some researchers indicated that there is a positive link between organizational culture and performance (Fay \& Denisson, 2003; Pirayeh et al, 2011). Literature review, indicate that a positive relationship exists between change management and organizational strategy implementation for example some studies imply that it is possible that the relationship between change management and turnaround strategy implementation would be, moderated by some yet unconsidered variables (Ahmadi et al., 2012; Ahmad et al., 2007). Collins.com (2013), defines organizational culture as the customs, rituals and values shared by the members of an organization that have to be accepted by new members, while BusinessDictionary.Com (2013), defines it as "the values and behaviors that contribute to the unique social and psychological environment of an organization". Ahmadi et al. (2012) claimed that, there was no consensus on comprehensive definition of organizational culture. They however, described it as a set of beliefs and shared values that unifies members of an organization consolidating them under the cover of potent behavioral norms and rules. The idea of no consensus on the definition of organizational culture was confirmed by Hatch and Zilber (2011), who pointed out that cultures were not accurately or completely described at all. Other researchers defined organizational culture as "beliefs, assumptions, and values that members of a group share about rules of conduct, leadership styles, administrative procedures, ritual, and customs" (Mintzburg, 1990; Schein, 1995; Mehta \& Krishnan, 2004).

Past studies on organizational culture maintain its relationship with performance and effectiveness (Fay \& Denison, 2003; Pirayeh, Mahdari, \& Nematpour, 2011). Ahmadi et al. (2012) confirmed that there was a positive link between organizational culture and strategy implementation. Mehta and Krishnan (2004), found that strong cultures help leaders to be more charismatic and influencial. Alvesson (1990) found that, culture can be used as a tool for achieving performance. Other studies indicate that culture therefore seemed to have some substancial influence on organization's strategy (Mantere, 2000; Van Der Maas, 2008; Van Buul, 2010). Some researchers suggest that it is necessary to change organizational culture in order to ensure successful fundamental change in some situations (LaMarsh, 1997; Peppard \& Fitzgerald, 1997). Ahmad et al. (2007) agrees with other researchers that a well-established culture of teamwork would make it easier for the organization to achieve its goals and therefore recommended that culture should become a top priority in BPR in order to move the whole organization to desirable ends. Some of the studies on organizational culture also indicate its relationship with organizational change (Rashid et al., 2004; Carnall, 1999).

The causal model of organizational performance and change shows that changes on the external environment that would touch on the organizational culture systems, are bound to further affect the individual needs and values of the people in it, which implies cuase - effect relationship. There is an existence of a positive link between organizational culture and strategy implementation (Ahmadi et al., 2012). A well established culture of team work would make it easier for an organization to achieve its goals (Ahmadi et al., 2007). Strong cultures help leaders to be more charismatic and influencial (Mehta \& Chrishnan, 2004).

Desson and Clouthier (2010) claimed that organizational culture was identifiable and known to have an effect on decision making and activities at all levels within an organization. The management ability to make 
good decisions will involve the managers competencies. Organizational culture has the ability to shape organization's capacity for and receptiveness to change as well as the ability to shape the speed and efficiency with which things are done which also has to do with the skills and competencies of the respective managers.

Desson and Clouthier (2010) further indicated that organizational culture was known to have an effect on management styles within an organization, further clarifying that organizational culture had the ability to shape the speed and efficiency with which things were done. Gieves (2000) postulated that if people were managed the right way so that they adapt to and adopt change, in the long run this would change cultural norms.

SHRM (2012) observed that a campany's structure and design would be viewed as its body, and its culture as its soul and further pointed out that if an organization's culture was to improve its overall performance and effectiveness, then its culture had to be strong and able to provide a strategic competitive advantage while its beliefs and values had to be widely shared and firmly upheld. Further observations indicated that, facilitating organizational learning from different viewpoints would also be beneficial in maximizing organizational structure, procedures and processes which imply that organizational culture does influence structure both positively and negatively. If managing people well would in the long run change cultural norms, then the manner in which people are handled within some organizational structure would either influence implementation of its turnaround strategy positively or negatively.

Mochal (2003) suggested that "even with sound project teams and plans in place, organization's project success rate may not be as high as it could be". He singled out culture as having a huge effect on organizational project success rates because of cultures presence in project orientation, governance, training, and roles and responsibilities all of which, would impact either negatively or positively on the implementation of turnaround strategy depending on the levels of culture at play. According to Schein, organizational culture and leadership (2004), culture can be analyzed at three major levels namely: artifacts, espoused beliefs and values, and underlying assumption. The second (espoused beliefs and values) level, reflects someone's beliefs and values, sense of what ought to be, strategies, goals, and philosophies may be ideal upon which organizational culture in this study may be operationalized.

According to Cameron and Quinn (1999) model, there are four types of culture. These are, hierarchy culture which focuses on internal efficiency, cooperation, and sticking to dominant characteristics; clan culture(family culture) which focus on internal issues but relies on flexibility rather than stability, which is characterised by partnership, teamwork, and corporate commitment to employees; market culture which is control oriented and mainly focuses on external organization affairs and is characterised by obsevation and resistance to reach higher level of productivity and competitiveness.; and adhocracy culture which focuses on external organization matters and lays ephasis on flexibility and change more than resistance. In order to measure organizational culture, the Organizational Culture Assessment Instrument (OCAI) which was developed by Cameron and Quinn (1999) is used to measure organizational culture by considering six dimensions namely: dominant characteristics, organizational leadership, management of employees, organizational glue, strategic emphasis, and criteria of success.

Since adhocracy culture focuses more on external organization matters with an ephasis on flexibility and change, the moderating effect of culture on turnaround strategy shall be measured by: formal procedures of governance; availability of coordinating, organizing, and smooth type of leadeship; job security, conformity, predictability and stability management styles; formal rules and policies organization glue; stability, efficiency and control in strategic emphasis; and criteria of success based on efficiency, low-cost production or dependable delivery. Although no specific case is, known that would demonstrate that change management leads to an improvement in terms of turnaround strategy implementation, the discussions on whether organizational culture has a moderating effect on turnaround strategy implementation, imply that indeed organizational culture would impact both positively and negatively on turnaround strategy implementation.

\section{Summary Discussions}

Organizational culture has an effect on decision-making and on other activities at all levels within the organizational, it also has the ability to shape organization's capacity for and receptiveness to change as well as the ability to shape the speed and efficiency with which things are done (Desson \& Clouthier, 2010). It is further proven that for an organization's culture to be able to improve its overall performance and effectiveness, it has to be strong and able to provide a strategic competitive advantage, while its beliefs and values need to be widely shared and firmly upheld (SHRM, 2012). Literature review also indicate that, culture has a huge effect on organizational project success rates because of its presence in project orientation, governance,, training, roles, and responsibilities (Mochal, 2003), all of which play a key role in turnaround strategy implementation. Organizational culture therefore, has a moderating effect between the business process reengineering CSFs turnaround strategy implementation. 


\section{Conclusion}

Effective implementation of turnaround strategy would depend on, success in realizing critical process improvements during the process by focusing on cost, quality, and time factors. The necessary generic business Turnaround strategies to address the three focus areas are improved sales and marketing, cost reduction, quality improvements, improved responsiveness, improved information and control systems. However, looking for remedial measures that would be used to address issues to do with tackling of turnaround implementation success rates one may start by considering the fact that, it is true that there is a positive link between organizational culture and strategy implementation (Ahmadi et al., 2012). This is further supported by the fact that, strong cultures help leaders to be more charismatic and influencial (Mehta \& Krishnan, 2004). Further exposure from literature reiew indicate that, well established culture of teamwork would make it easier for an organization to achieveits goals (Ahmad et al., 2007). The sentiments above would be effectively used to identify how best organizational culture would apply in moderating specific factors for the achievement of best turnaround strategy implementation success rates for the benefit of the ever increasing business failures in many economies of the worl today.

\section{Recommendations}

It is recommended that empirical studies be carried out to establish:

1. The effect of business process reengineering CSFs and how they would be effectively used to enhance the success rates in turnaround strategy implementation.

2. The impact of the moderating effect of organizational culture between various change initiatives such as business process reengineering or total quality management TQM and others in the same category with a view to finding improved turnaround strategy implementation rates.

\section{References}

[1]. Ahmad, H., Francis, A., \& Zairi, M. (2007). Business Process Reengineering: Critical success factors in higher education. Business Process Management Journal, 13(3), 451-469.

[2]. Ahmadi, S., Salamzadeh, Y., Daraei, M., \& Akbari, J. (2012). Relationship between organizational culture and strategy implementation: typologies and dimensions. Global Business and Management Research: An International Journal.

[3]. Al-Mashari, M., \& Zairi, M. (1999). BPR implementation process: An analysis of key success and failure factors. Business Process Management Journal, 5.

[4]. Alvesson, M. (1990). On the Popularity of Organizational Culture. ActaSociologica, 33(1), 31-49.

[5]. Burbank, R. K. (2005). The classic five-step turnaround process: Case study of Prodigene Inc. The Journal of Private Equity(Special Turnaround issue), 53-58.

[6]. Burke, W. W., \& Litwin, G. H. (1992). A causal model of organizational performance and change. Journal of management, 18.

[7]. BusinessDictionary.Com. (2013). What is Organizational Culturew? definintion and meaning. Retrieved 9 02, 2013, from BusinessDictionary.com: http://www.businessdictionary.com/definition/organizational-culture.html

[8]. Cameron, K., \& Quinn, R. (1999). Diagnosingand Changing Organizational Culture. Based on the Competing Values Framework. Boston: Addison-Wesley.

[9]. Carnall, C. A. (1999). Managing Change in Organizations. UK/Hemel Hempstead: Prentice - Hall International.

[10]. Collins.com. (2013). Definition of Organizational Culture. Retrieved 9 02, 2013, from Collins Dictionaries: http://www.collinsdictionary.com/dictionary/english/organizational-culture

[11]. Desson, K., \& Clouthier, J. (2010). Organizational culture - When does it matter? Symposium on International Safeguards, International Atomic Energy Agency, (pp. 1-9). Vienna.

[12]. Fay, C. F., \& Denison, D. R. (2003). Organizational Culture and Effectiveness: Can American Theory be Applied in Russia? Organizational Science, 14(6), 686-706.

[13]. Francis, J. D., \& Desai, A. B. (2005). Situational and organizational determinants of turnarounds. Management Decision , 43(9), 1203-1224.

[14]. Gieves, J. (2000). Introductions: the origins of organizational development. Journal of Management Development, 19(5), $345-447$.

[15]. Haron, N. H., Rahman, I. K., \& Smith, M. (2013). Management accounting practices and the turnaround process. Asian Review of Accounting, 21(2), 100-112.

[16]. Hatch, M. J., \& Zilber, T. (2011). Conversation at the Border between Organizational Culture Theory and Institutional Theory. Journal of Management Inquiry, 21(1), 94-97.

[17]. Hofer, C. W. (1980). Business turnaround strategies. Jounal of Busines Strategy, 1.

[18]. John, A. P., \& Richard, B. R. (1987). Corporate Strategies: Aselection of Readings from Business Week (Inter ed.). New York: McGraw Hill.

[19]. LaMarsh, J. (1997). The resilient worker: employees who can cope with change. Hospital Material Management Quarterly, 19(2), pp. 54-8.

[20]. Lohrke, F., Bedeian, A. C., \& Palmer, T. (2004). The role of top management teams in formulating and implementing business turnaround strategies: A review and research agenda. International Journal of Management Reviews, 5.

[21]. Maheshwari, S. K. (2000, October-December). Organizational decline and turnaround management: A contigency framework. Vikalpa, 25(4).

[22]. Maheshwari, S. K., \& Ahlstrom, D. (2003). Turning around a state owned enterprise: The case of scooters in India Limited. Asia Pacific Journal of Management Conference on Corporate Turnaround, (pp. 75-101).

[23]. Manimala, M. J., \& Panicker, S. (2011). Successful business turnaround: The role of appropriate entrepreneural strategies. Indian Institute of Management.

[24]. Mantere, S. (2000). Sensemaking in Strategy Implementation. Master Thesis, Helsinki University of Technology, Finland. 
[25]. Mehta, S., \& Krishnan, V. R. (2004). Impact of Organizational Culture and Influence Tacts on Transformational Leadership. Journal of Management and Labour Studies , 29(4), 281-290.

[26]. Mintzburg, H. (1990). Strategy formation: schools of thought. perspectives on strategic management,. New York: Harper Business.

[27]. Mochal, T. (2003, July 2). Organizational culture and structure influence project management more than you realize. Retrieved November 27, 2013, from TechRepublic: http://www.techrepublic.com/article/organizational-culture-and-structure-influenceproject-management-more-than-you-realize/

[28]. Pandit, N. (2000). Some recommendations for improved research on corporate business turnaround. Academy of Management Review, 3.

[29]. Peppard, J., \& Fitzgerald, D. (1997). The transfer of culturally-grounded managementtechniques: the case of business process reengineering in Germany. European Management Journal, 15(4), 446-60.

[30]. Pirayeh, N., Mahdari, A. M., \& Nematpour, A. M. (2011). Study of Organizational Culture Influence (Based on Dennison's Model) on Effectiveness of Human Resources in Karun Oil \& Gas Production Company. Australian Journal of Basic and Applied Sciences, 5(9), 1886-1895.

[31]. Pretorius, M. (2009). Defining business decline, failure and turnaround: A content analysis. SAJESBM NS, 2(1), 1-16.

[32]. Rashid, M. Z., Sambasiavn, M., \& AdbulRahhman, A. (2004). The influence of organizational culture on attitudes towards organizational change. Leadership \& Organizational Development Journal, 25(2), 161-179.

[33]. Rosario, R. H., Kawamura, T., \& Peiris, T. L. (2004). The Coir Fiber Industry in Sri Lanka: Reasons for its decline and possible business turnaround strategies. Agribusiness, 20.

[34]. Schein, E. H. (1995). Organizational and managerial culture as a facilitator or inhibitor of organizational transformation. Cambridge: MIT Sloan School of Management.

[35]. Schein, E. H. (2004). Organizational culture and leadership (3rd ed.). San Francisco: John Willey \& Sons.

[36]. Scherrer, P. S. (2003). Management business turnaround: diagnosing business ailments. Corporate Governance, 3.

[37]. SHRM. (2012, November 30). Organizational Culture: Does a company's culture affect organizational performance and effectiveness. Retrieved November 27, 2013, from Society for Human Resource Management: http://www.shrm.org/TemplatesTools/hrqa/Pages/Doesacompany\%E2\%80\%99scultureaffectorganizationalperformanceandeffective ness.aspx

[38]. Slatter, S., Lovett, D., \& Barlow, L. (2006). Leading corporate business turnaround: How leaders fix troubled companies.

[39]. Turnaroundstrategy.net. (2013, 11 13). Turnaround Strategy. Retrieved 2013, from Turnaroundstrategy.net: http://www.turnaroundstrategy.net/

[40]. Van Buul, M. (2010). Successful Straregy Implementation: A job for the Internal Auditor? Master Thesis, University of Amsterdam, Netherlands.

[41]. Van Der Maas, A. A. (2008). Strategy Implementation in Small Island Community. PhD Thesis, Erasmus University of Rotterdam, Netherlands.

[42]. Wheelen, T., \& Hunger, J. (2001). Strategic Management and Business Policy. Addison Wesley Reading. 